\title{
PERBEDAAN LEBAR GIGI ANTERIOR RAHANG ATAS DENGAN KONSEP GOLDEN PROPORTION PADA MAHASISWA FKG UNIVERSITAS ANDALAS SUKU MINANG
}

\author{
Riani Hafiza ${ }^{1}$, Fadil Oenzil ${ }^{2}$, Murniwati ${ }^{1}$ \\ ${ }^{1}$ Mahasiswa Fakultas Kedokteran Gigi Universitas Andalas \\ ${ }^{2}$ Staf Pengajar Fakultas Kedokteran Universitas Andalas \\ ${ }^{3}$ Staf Pengajar Fakultas Kedokteran Gigi Universitas Andalas
}

\begin{abstract}
Background: One of the parameter that can represent the ideal beauty is the concept of the golden proportion. The proportion on teeth can be seen from frontal view. The width of the central incisor is $62 \%$ wider than the width of the lateral incisor. The width of the lateral incisor is $62 \%$ wider than the visible part of canine. One of the factors that affect the size of the tooth is race. Minang ethnic is included to Malay Deutro. Purpose: The purpose of this study is to determine the difference of the width of maxillary anterior teeth with the concept of the golden proportion in Minang ethnic students of Faculty of Dentistry, Andalas University. Methods: The study was an analytic observasional with cross-sectional approach. The sampling was purposive sampling and the number of subjects were 26 respondents. Photographs of the respondents were taken at least three times each using a digital camera Sony Cyber-shot DSC-S3000 10.1 MP, edited using software Adobe Photoshop CS5 and analyzed using paired sample $t$ test. Result: The result of paired sample t test is $p=0.000$ ( $p<0.05)$. This suggests there is a significant difference between the width of maxillary anterior teeth with the concept of the golden proportion in Minang ethnic students of Faculty of Dentistry, Andalas University. The proportion of the width of maxillary anterior teeth from the frontal view according to golden proportion $1.62: 1: 0.62$, when it comes to Minang ethnic students of Faculty of Dentistry, Andalas University, it is measured as $1.51: 1: 0.76$ for right region and $1.52: 1: 0.77$ for left one. Conclusion: The

concept of the golden proportion can not be used to Minang ethnic students of Faculty of Dentistry, Andalas University.
\end{abstract}

Keywords: aesthetic, anterior teeth, golden proportion, maxillary, Minang ethnic

Affiliasi penulis : 1. Fakultas Kedokteran Gigi Universitas Andalas, 2.Bagian Biokimia Fakultas Kedokteran Universitas Andalas

Korespondensi :Riani Hafiza, email: hafizariani@yahoo.com,

\section{PENDAHULUAN}

Salah satu isu yang sering diperdebatkan dalam estetika atau keindahan adalah apakah estetika dapat diukur oleh parameter yang objektif atau hanya tergantung pada subjektif belaka. Salah satu parameter yang dapat mewakili keindahan yang ideal, yaitu konsep golden proportion. Konsep golden proportion menciptakan nilai yang membuat kita melihat rangsangan estetik yang sama dengan cara yang terkontrol. ${ }^{1}$

Konsep golden proportion dijelaskan secara geometri pertama kali pada abad ke 4 SM oleh Euclid sebagai sebuah pembagian unik dari sebuah garis $(A B)$ menjadi dua bagian ( $\mathrm{AC}$ dan $\mathrm{BC}$ ), perbandingan garis yaitu " $\mathrm{AB}: \mathrm{AC}=\mathrm{AC}$ : CB".2 Euclid menjelaskan ini pada The 
Elements, sebuah karangannya di bidang matematika. Original dari konsep ini tidak diketahui, sepertinya memiliki hubungan antara Phytagoras dan Plato. ${ }^{3}$

Proporsi ini menyatakan hubungan antara bagian yang terbesar dengan bagian terkecil dari sebuah objek. Simbol dari golden proportion yaitu phi $(\varphi)$, sebuah simbol Yunani yang diambil dari seorang seniman Yunani kuno Phidias yang dikenal menggunakan konsep ini pada pekerjaannya, yaitu Parthenon. ${ }^{3}$ Selain Euclid, juga ada Fibonnanci yang menjelaskan golden proportion sebagai phi $(\varphi)$ sama dengan ${ }^{1,618.2}$

PProporsi ini telah digunakan di dunia dalam berbagai kegiatan, diantaranya oleh seniman, ahli matematika, arsitek dan ahli mesin untuk belajar dan mendesain proporsi pada seni dan alam. ${ }^{4}$ Aplikasi konsep ini dalam kedokteran gigi pertama kali diuji oleh Lambordi, kemudian Levin menetapkan proporsi ini dipakai pada gigi jika diamati dari depan (frontal). ${ }^{5}$ Lebar gigi yang diamati dari depan berbeda dengan lebar gigi yang sebenarnya, disebabkan oleh kelengkungan dari lengkung gigi. $^{6}$ Permukaan dari gigi anterior rahang atas yang sesuai dengan konsep terdiri dari bagian: lebar gigi insisivus sentral (CI) dengan lebar gigi insisivus lateral (LI) dan lebar gigi insisivus lateral dengan lebar gigi kaninus (C). ${ }^{5}$ Proporsinya yaitu lebar gigi insisivus sentral $62 \%$ lebih lebar dari lebar gigi insisivus lateral, lalu lebar gigi insisivus lateral $62 \%$ lebih lebar dari bagian terlihat dari kaninus. Mengacu dari hasil penelitian Levin, proporsi ini diperkenalkan pada beberapa buku pelajaran sebagai sebuah prinsip estetik untuk restorasi dari gigi depan. $^{7}$

Fayyad et al, melakukan penelitian mengenai hubungan proporsi gigi anterior rahang atas dengan konsep golden proportion pada penduduk asli Arab yang mewakili ras Kaukasoid. Rata-rata proporsi dari gigi insisivus sentral, insisivus lateral, dan kaninus rahang atas yang didapat pada penelitiannya adalah $1,53: 1: 0,8.8$ Forster et al, juga melakukan penelitian tentang proporsi lebar gigi anterior rahang atas pada populasi Hungaria. Hasil penelitiannya lebar relatif dari insisivus sentral, insisivus lateral dan kaninus adalah 1,6 : $1: 0,85$ pada kedua sisi (Forster et al, 2013). ${ }^{9}$ Di Indonesia, Daulay juga melakukan penelitian tentang proporsi lebar gigi insisivus sentral 
dan lateral rahang atas dan hubungannya dengan konsep golden proportion pada mahasiswa FKG USU. Hasil penelitiannya mendapatkan proporsi 1,43 : 1 untuk regio kanan rahang atas dan $1,46: 1$ untuk regio kiri rahang atas. ${ }^{10}$

Salah satu faktor yang mempengaruhi ukuran gigi adalah ras. Setiap ras memiliki ciri khasnya masingmasing. ${ }^{11}$ Beberapa penelitian telah menunjukkan proporsi lebar gigi anterior rahang atas pada beberapa ras. Ras yang terpenting di dunia meliputi Kaukasoid, Mongoloid, dan Negroid. $^{12}$ Ras Mongoloid memiliki subras yaitu Mongoloid Melayu atau ras Melayu.13 Indonesia merupakan salah satu bagian yang memiliki subras Mongoloid Melayu ini. ${ }^{13,14}$ Subras Mongoloid Melayu di Indonesia terbagi menjadi dua yaitu Deutro Melayu dan Proto Melayu. ${ }^{15}$

Kampus Fakultas Kedokteran Gigi Universitas Andalas berlokasi di Padang, Sumatera Barat. Seluruh mahasiswanya merupakan warga negara asli Indonesia. Beberapa suku yang mendiami Sumatera Barat adalah suku Minang, suku Mentawai dan suku Nias. Menurut Koentjaraningrat, suku Nias dan suku Mentawai merupakan ras Proto Melayu yang berasal dari Yunan sekitar 2000 tahun
SM dan datang ke Indonesia melalui jalur Indocina melewati semenanjung Malaya ke Sumatera. Sedangkan suku Minang merupakan ras Deutro Melayu yang berasal dari daerah teluk Tonkin (Vietnam utara) sekitar 500 tahun SM.16 Berdasarkan uraian diatas, peneliti ingin meneliti perbedaan lebar gigi anterior rahang atas (insisivus sentral, insisivus lateral dan kaninus) dengan konsep golden proportion pada mahasiswa FKG Universitas Andalas suku Minang.

\section{METODE}

Desain penelitian yang digunakan adalah observasional analitik dengan pendekatan cross sectional. Pemilihan sampel dengan cara purposive sampling dengan besar sampel dalam penelitian ini adalah 26 responden.

Pada 26 responden dilakukan pengambilan gambar gigi responden dengan kamera digital dan tripod. Jarak kamera dengan subjek diatur sama setiap pengambilan gambar tiap responden. Responden diposisikan dengan posisi dagu bertumpu pada tempat tumpuan dagu. Dataran horizontal frankfurt sejajar lantai, kepala sejajar dengan kamera. Responden diminta untuk senyum dengan minimal garis senyum medium, 
yaitu terlihat antara 50\%-100\% tinggi insisal dari gigi anterior rahang atas dan papilla terlihat pada senyuman natural, marginal gingiva tidak terlihat. Dilakukan pengambilan foto dengan minimal tiga kali pengambilan.

Hasil foto kemudian dilakukan pengeditan. Pengeditan dilakukan dengan menggunakan software editing photo (Adobe Photoshop CS5). Dibuat garis median line dan dibuat titik paling distal dan paling mesial dari gigi insisivus sentral, insisivus lateral serta kaninus kanan dan kiri rahang atas. Setelah itu dibuat garis vertikal pada titik-titik tersebut sejajar garis median line.

Setelah pengeditan selesai, foto dicetak dengan ukuran yang sama lalu dilakukan pengukuran. Pengukuran lebar masing-masing gigi anterior rahang atas diukur dengan menggunakan sliding kaliper. Hasil yang didapat dimasukkan dalam master tabel, kemudian dilakukan analisis statistik menggunakan uji Paired Sample T Test.

\section{HASIL}

Distribusi rata-rata lebar gigi anterior rahang atas yang diukur pada foto gigi mahasiswa FKG Universitas Andalas suku Minang dapat dilihat pada tabel 1 berikut.
Tabel 1. Lebar gigi anterior rahang atas difoto

\begin{tabular}{ccccc}
\hline Gigi & $\begin{array}{c}\text { Rata- } \\
\text { rata } \\
(\mathbf{m m})\end{array}$ & $\begin{array}{c}\text { Standar } \\
\text { Deviasi } \\
(\mathbf{m m})\end{array}$ & $\begin{array}{c}\text { Minimun } \\
(\mathbf{m m})\end{array}$ & $\begin{array}{c}\text { Maksimun } \\
(\mathbf{m m})\end{array}$ \\
\hline 11 & 8,27 & 0,35 & 7,4 & 8,8 \\
12 & 5,49 & 0,37 & 4,6 & 6,1 \\
13 & 4,13 & 0,54 & 3,3 & 5,5 \\
21 & 8,30 & 0,35 & 7,5 & 9,2 \\
22 & 5,49 & 0,39 & 4,7 & 6,1 \\
23 & 4,24 & 0,44 & 3,3 & 4,9 \\
IC & 35,92 & 1,43 & 33,5 & 39,3 \\
\hline IC : Interkaninus & & &
\end{tabular}

$\mathrm{mm}$, nilai terkecilnya $7,4 \mathrm{~mm}$ dan terbesarnya $8,8 \mathrm{~mm}$. Rata-rata lebar gigi insisivus lateral rahang atas kanan $5,49 \pm 0,37 \mathrm{~mm}$, nilai terkecilnya $4,6 \mathrm{~mm}$ dan terbesarnya 6,1 mm. Rata-rata lebar gigi kaninus rahang atas kanan $4,13 \pm 0,54 \mathrm{~mm}$, nilai terkecilnya $3,3 \mathrm{~mm}$ dan terbesarnya $5,5 \mathrm{~mm}$. Rata-rata lebar gigi insisivus sentral rahang atas kiri $8,30 \pm 0,35 \mathrm{~mm}$, nilai terkecilnya $7,5 \mathrm{~mm}$ dan terbesarnya 9,2 $\mathrm{mm}$. Rata-rata lebar gigi insisivus lateral rahang atas kiri $5,49 \pm 0,39 \mathrm{~mm}$, nilai terkecilnya $4,7 \mathrm{~mm}$ dan terbesarnya 6,1 $\mathrm{mm}$. Rata-rata lebar gigi kaninus rahang atas kiri 4,24 $\pm 0,44$ $\mathrm{mm}$, nilai terkecilnya $3,3 \mathrm{~mm}$ dan terbesarnya 4,9 mm. Rata-rata lebar interkaninus rahang atas 35,92 $\pm 1,43$ $\mathrm{mm}$, nilai terkecilnya $33,5 \mathrm{~mm}$ dan terbesarnya $39,3 \mathrm{~mm}$.

Distribusi rata-rata lebar gigi anterior rahang atas menurut konsep golden proportion dapat dilihat pada tabel 2 berikut. 
Tabel 2. Lebar gigi anterior rahang atas menurut konsep golden proportion

\begin{tabular}{ccccc}
\hline Gigi & $\begin{array}{c}\text { Rata- } \\
\text { rata } \\
(\mathbf{m m})\end{array}$ & $\begin{array}{c}\text { Standar } \\
\text { Deviasi } \\
(\mathbf{m m})\end{array}$ & $\begin{array}{c}\text { Minimun } \\
(\mathbf{m m})\end{array}$ & $\begin{array}{c}\text { Maksimun } \\
(\mathbf{m m})\end{array}$ \\
\hline 11 & 8,90 & 0,60 & 7,45 & 9,88 \\
12 & 5,49 & 0,37 & 4,60 & 6,10 \\
13 & 3,41 & 0,23 & 2,85 & 3,78 \\
21 & 8,90 & 0,63 & 7,61 & 9,88 \\
22 & 5,49 & 0,39 & 4,70 & 6,10 \\
23 & 3,40 & 0,24 & 2,91 & 3,78 \\
\hline
\end{tabular}

proportion adalah $8,90 \pm 0,60 \mathrm{~mm}$, nilai terkecilnya $7,45 \mathrm{~mm}$ dan terbesarnya 9,88 mm. Rata-rata lebar gigi insisivus lateral rahang atas kanan 5,49 $\pm 0,37$ $\mathrm{mm}$, nilai terkecilnya $4,6 \mathrm{~mm}$ dan terbesarnya 6,1 $\mathrm{mm}$. Rata-rata lebar gigi kaninus rahang atas kanan 3,41 $\pm 0,23$ $\mathrm{mm}$, nilai terkecilnya $2,85 \mathrm{~mm}$ dan terbesarnya 3,78 $\mathrm{mm}$. Rata-rata lebar gigi insisivus sentral rahang atas kiri $8,90 \pm 0,63 \mathrm{~mm}$, nilai terkecilnya 7,61 $\mathrm{mm}$ dan terbesarnya $9,88 \mathrm{~mm}$. Rata-rata lebar gigi insisivus lateral rahang atas kiri $5,49 \pm 0,39 \mathrm{~mm}$, nilai terkecilnya $4,7 \mathrm{~mm}$ dan terbesarnya 6,1 $\mathrm{mm}$. Rata-rata lebar

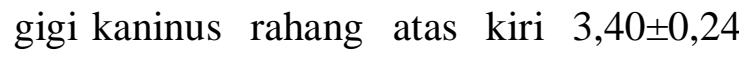
$\mathrm{mm}$, nilai terkecilnya $2,91 \mathrm{~mm}$ dan terbesarnya $3,78 \mathrm{~mm}$.

Tabel 3 dapat dilihat rata-rata proporsi lebar gigi anterior rahang atas pada mahasiswa FKG Universitas Andalas Suku Minang. Rata-rata proporsi lebar gigi anterior rahang atas kanan adalah $1,51: 1: 0,76$ dan rata-rata proporsi lebar gigi anterior rahang atas kiri adalah 1,52: $1: 0,77$.

Tabel 3. Proporsi lebar gigi anterior rahang atas

\begin{tabular}{l}
\hline \multicolumn{1}{c}{ Regio Kanan } \\
\hline $\begin{array}{l}\text { Proporsi Lebar Gigi } \\
\text { Anterior Rahang } \\
\text { Atas }\end{array}$ \\
\hline Rahang Atas dengan Konsep Golden \\
Proportion pada Mahasiswa FKG \\
Universitas Andalas Suku Minang dapat \\
dilihat pada tabel 4 berikut.
\end{tabular}

Tabel 4. Perbedaan Lebar gigi Anterior Rahang Atas

\begin{tabular}{ccc}
\hline Gigi & $\begin{array}{c}\text { Selisih rata-rata } \\
(\mathbf{m m})\end{array}$ & $p$ \\
\hline 11 & $-0,62$ & 0,000 \\
13 & 0,72 & 0,000 \\
21 & $-0,59$ & 0,000 \\
23 & 0,83 & 0,000 \\
\hline
\end{tabular}

antara lebar gigi anterior rahang atas dengan konsep golden proportion pada mahasiswa FKG Universitas Andalas Suku Minang. Selisih rata-rata antara lebar gigi insisivus sentral kanan rahang atas dengan konsep golden proportion adalah $-0,62 \mathrm{~mm}$ dengan nilai $\mathrm{p}=0,000$ $(\mathrm{p}<0,05)$. Selisih rata-rata antara lebar gigi kaninus kanan rahang atas dengan konsep golden proportion adalah $0,72 \mathrm{~mm}$ dengan nilai $\mathrm{p}=0,000 \quad(\mathrm{p}<0,05)$. Selisih rata-rata antara lebar gigi insisivus sentral kiri rahang atas dengan konsep golden proportion adalah $-0,59 \mathrm{~mm}$ 
dengan nilai $p=0,000 \quad(p<0,05)$. Selisih antara lebar gigi kaninus kanan rahang atas dengan konsep golden proportion adalah $0,83 \mathrm{~mm}$ dengan nilai $\mathrm{p}=0,000$ $(\mathrm{p}<0,05)$.

\section{PEMBAHASAN}

Penelitian ini dilakukan pada 26 foto gigi mahasiswa $\mathrm{FKG}$ Universitas Andalas suku Minang. Hasil analisis bivariat dengan menggunakan Paired Sample $\mathrm{T}$ Test memperlihatkan nilai $\mathrm{p}$ yang diperoleh yaitu $\mathrm{p}=0,000 \quad(\mathrm{p}<0,05)$ antara lebar gigi anterior rahang atas dengan konsep golden proportion pada mahasiswa FKG Universitas Andalas suku Minang. Hasil ini memperlihatkan bahwa terdapat perbedaan yang signifikan antara lebar gigi anterior rahang atas dengan konsep golden proportion pada 26 responden mahasiswa FKG Universitas Andalas suku Minang.

Gigi insisivus sentral regio kanan maupun regio kiri memiliki selisih ratarata antara lebar gigi anterior rahang atas difoto dengan lebar menurut konsep golden proportion masing-masing yaitu 0,62 dan -0,59. Hal ini memperlihatkan bahwa lebar menurut konsep lebih lebar dari pada lebar yang ada pada foto. Pada gigi kaninus baik regio kanan maupun regio kiri memiliki selisih rata-rata antara lebar gigi anterior rahang atas difoto dengan lebar menurut konsep golden proportion masing-masing yaitu 0,72 dan 0,83. Hal ini memperlihatkan bahwa lebar menurut konsep lebih kecil dari pada lebar yang ada pada foto.

Dari hasil pengukuran lebar gigi anterior rahang atas responden, diperoleh proporsi lebar gigi anterior rahang atas yang dilihat dari arah depan yaitu 1,51: 1 : 0,76 untuk regio kanan dan 1,52 : 1 : 0,77 untuk regio kiri. Hasil ini berbeda dari konsep golden proportion yaitu 1,62 : 1 : 0,62 yang memperlihatkan bahwa proporsi antara lebar gigi insisivus sentral dengan lebar gigi insisivus lateral lebih kecil dari konsep golden proportion dan proporsi antara lebar gigi insisivus lateral dengan lebar kaninus lebih besar dari konsep golden proportion.

Penelitian sebelumnya yang dilakukan oleh Fayyad pada populasi Arab asli, dan penelitian Daulay pada populasi Indonesia menunjukkan hal yang sama.8,10 Fayyad melakukan penelitian pada populasi Arab asli dengan hasil penelitian 1,53 : 1 : 0,8.8 Hasil penelitian Fayyad ini berbeda dengan konsep golden proportion dan berbeda dengan penelitian ini, tetapi memiliki karakteristik yang sama dengan penelitian ini, yaitu 
proporsi antara lebar gigi insisivus sentral dengan lebar gigi insisivus lateral lebih kecil dari konsep golden proportion dan proporsi antara lebar gigi insisivus lateral dengan lebar gigi kaninus lebih lebar dari konsep golden proportion.

Daulay melakukan penelitian pada populasi Indonesia pada lebar gigi insisivus sentral dan insisivus lateral rahang atas dengan hasil penelitiannya 1,43 : 1 pada regio kanan dan 1,46:1 pada regio kiri.10 Hasil penelitian Daulay ini berbeda dengan konsep golden proportion dan juga berbeda dengan penelitian ini, tetapi memiliki karakteristik yang sama dengan penelitian ini, yaitu proporsi antara lebar gigi insisivus sentral dengan lebar gigi insisivus lateral lebih kecil dari konsep golden proportion.

Perbedaan dari hasil penelitian ini disebabkan karena perbedaan populasi dari responden penelitian Pada penelitian ini, peneliti melakukan penelitian pada responden suku Minang yang merupakan bagian dari ras Deutro Melayu. Daulay melakukan penelitian pada ras Mongoloid secara umum, dan Fayyad melakukan penelitian pada ras Kaukasoid.8,10
Perbedaan ras akan memiliki ciriciri umum fisik yang berbeda antara satu ras dengan ras yang lain disebabkan oleh adanya variasi ciri fisik pada masing-masing populasi tersebut. Ciri fisik pada masing-masing populasi tersebut dapat dilihat pada kulit, rambut, bentuk kepala, bentuk wajah, hidung, mata, tinggi badan dan gigi geligi.13,17

Bentuk kepala biasanya sesuai dengan bentuk lengkung rahang atas.18 Bentuk kepala Brachycephalic memiliki bentuk lengkung rahang luas atau persegi (square), Doligocephalic memiliki bentuk lengkung rahang sempit atau lancip (tapered), dan Mesocephalic memiliki bentuk lengkung rahang rata- rata atau parabola (ovoid).19

Dalam penelitian yang dilakukan oleh Tajik et al, selain bentuk muka, bentuk wajah juga memiliki hubungan dengan bentuk lengkung gigi. Bentuk kepala Brachycephali, memiliki wajah Euryprosopic atau wajah yang pendek dengan bentuk lengkung gigi yang square. Bentuk kepala Doligocephalic, memiliki wajah Leptoprosopic atau lonjong dengan bentuk lengkung gigi yang berbentuk tapered. Bentuk kepala Mesocephalic, memiliki wajah Mesoprosopic memiliki bentuk lengkung 
diantara keduanya atau biasa disebut tipe normal atau rata-rata.20 Pada penelitian Irsa, bentuk kepala suku Minang berdasarkan indeks cephalic tergolong pada tipe Mesocephalic.16 Menurut Ardhana dan Tajik, bentuk kepala Mesocephalic, memiliki bentuk lengkung rahang rata-rata atau disebut juga parabola (ovoid).19,20

Variasi bentuk lengkung rahang akan membuat proporsi lebar gigi terlihat dari arah depanyang akan terlihat berbeda.6 Hal ini menjelaskan bahwa perbedaan ras akan menghasilkan proporsi lebar gigi yang terlihat dari arah depan akan berbeda juga.

Pola kehidupan sosial dan kepercayaan yang dianut suatu kelompok adalah faktor penting yang mempengaruhi cara hidup dan perkawinan suatu populasi.16 Sebagian besar masyarakat di dunia menarik garis keturunannya adalah dari pihak ayah (patrilineal) atau dari pihak ayah dan ibu sekaligus (parental). Bagi masyarakat Minangkabau, mereka menarik garis keturunan dari pihak ibu atau matrilineal.13 Perbedaan pola menarik garis keturunan akan berpengaruh pada pola perkawinan. Pola perkawinan yang berbeda di dalam kelompok suku akan menghasilkan perbedaan genetis secara turun- temurun.16

Dalam melakukan penelitian ini memiliki keterbatasan. Keterbatasan dalam penelitian ini adalah pemilihan responden tidak memperhatikan bentuk kepala dan bentuk wajah yang akan mempengaruhi bentuk lengkung dari responden. Bentuk lengkung dapat mempengaruhi lebar gigi yang dilihat dari arah depan.

\section{KESIMPULAN}

Berdasarkan

penelitian yang dilakukan pada 26 orang responden dari mahasiswa FKG Universitas Andalas Suku Minang, diperoleh kesimpulan sebagai berikut :

1. Rerata lebar gigi anterior rahang atas yang dilihat dari arah depan pada mahasiswa FKG Universitas Andalas yaitu : a. Gigi insisivus sentral regio kanan $8,27 \pm 0,35 \mathrm{~mm}$ b. Gigi insisivus lateral regio kanan $5,49 \pm 0,37 \mathrm{~mm}$ c. Gigi kaninus regio kanan 4,13 $\pm 0,54 \mathrm{~mm}$ d. Gigi insisivus sentral regio kiri 8,30 $\pm 0,35$ $\mathrm{mm}$ e. Gigi insisivus lateral regio

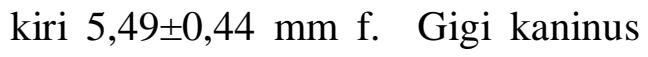
regio kiri 4,24 $\pm 0,44 \mathrm{~mm}$

2. Rerata proporsi lebar gigi anterior rahang atas yang dilihat dari arah 
depan pada mahasiswa FKG Universitas Andalas Suku Minang yaitu 1,51: 1 : 0,76 untuk regio kanan dan 1,52: $1: 0,77$ untuk regio kiri.

3. Terdapat perbedaan yang signifikan antara lebar gigi anterior rahang atas dengan konsep golden proportion pada mahasiswa FKG Universitas

Andalas suku Minang, sehingga konsep golden proportion tidak bisa dipakai pada mahasiswa FKG Universitas Andalas suku Minang karena memiliki perbedaan yang signifikan

\section{KEPUSTAKAAN}

1. Dio, CD., Macaluso, E., \& Rizzolatti, G (2007). The Golden Beauty: Brain Response to Classical and Renaissance Sculptures. PLoS one, 2(11)

2. Kiekens, RMA., Jagtman, AMK., Hof, MAV., \& Hof, BEV (2008). Putative Golden Proportion as Predictors of Facial Esthetics in Adolescent. Am J Orthod Dentofacial Orthop, 134: 480-30

3. Naini, FB., Moss, JP., \& Gill, DS (2006). The Enigma of Facial Beauty: Esthetics, Proportions, Deformity, and Controversy. Am J Orthod Dentofacial Orthop, 130: 277-82

4. Paul, MMC., \& Abraham, ST (2013). Golden Proportion in Denture Esthetics. Health Sciences, 2(1): JS008

5. Rita, ME., Kinga, Janosi., Carmen, Biris., Diana, Cerghizan., C, Horga., B, Bogozi., et al. (2013). Aesthetic Principles of the Upper Front Teeth: Application of the Golden Proportion (Levin) and Golden
Percentage (Snow). Acta Medica Marisiensis, 59(1): 25-27

6. Naini, Farhad B (2011). Facial Aesthetics Concepts \& Clinical Diagnosis. WileyBlackwell. India

7. Patil, Ranadeep (2002). Esthetic Dentistry an Artistis Science. PR Publications. India

8. Fayyad, MA., Jamani, KD., \& Agrabawai, J (2006). Geometric and Mathematical Proportions and their Relations to Maxill ary Anterior Teeth. The Journal of Contemporary Dental Practice, 7(5)

9. Forster, A., Velez, R., Antal, M., \& Nagy, K (2013). Width Ratios in The Anterior Maxillary Region in A Hungarian Population: Addition to the Golden Proportion Debate. J Prosthet Dent, 110:211-215

10. Daulay, Novi Wahyuni (2009). Proporsi Lebar Gigi Insisivus Sentralis dan Lateralis Rahang Atas dan Hubungannya dengan Konsep Golden Proportion pada Mahasiswa FKG-USU Tahun Angkatan 2006-2008 [Skripsi]. Medan. Universitas Sumatera Utara

11. Rahardjo, P (2008). Diagnostis Ortodonti. Airlangga University Press. Surabaya

12. Noviasari, W. \& Untari, S. (2013). Perbedaan Deprivasi Relatif Fraternal antara Etnis Cina dan Etnis Jawa. Talenta Psikologi, 2(1)

13. Takari, M., Harahap, FD., Fadlin., Nasborhu, T., Netripoza, A., \& Dewi, H (2008). Masyarakat Kesenian di Indonesia. Studi Kultural. Universitas Sumatera Utara

14. Rieuwpassa, IE., Toppo, S., \& Haerawati, SD (2012). Perbedaan Ukuran dan Bentuk Lengkung Gigi antara Laki-Laki dan Perempuan suku Bugis, Makassar, dan Toraja. Dentofacial, 11(3): 156-160

15. Hartini, D (2011). Masyarakat Prasejarah Indonesia. Diakses 2 November 2014; http://perpus.smkn1madiun.net/normatif/se jarah/1_1_masyarakat_prasejarah_indonesi a/index.htm

16. Irsa, R., Syaifullah., \& Tjang, DH (2013). Variasi Kefalometri pada Beberapa Suku di Sumatera Barat. Jurnal Biologi Universitas Andalas, 2(2): 130-137 17. 
Haviland, WA (1999). Antropologi, 4th edn. Trans.Soekadijo, RG. Erlangga. Jakarta

17. Gunadi, Haryanto A., Margo, Anton., Burhan, Lusiana K., Suryatenggara, Freddy., \& Setiabudi, Indra (1991). Buku Ajar Ilmu Geligi Tiruan Sebagian Lepasan. Hipokrates. Jakarta

18. Ardhana, Wayan (2009). Ortodonsia I Prosedur Pemeriksaan Ortodontik. Fakultas Kedokteran Gigi Universitas Gajah Mada 20. Tajik, Imran., Mushtaq, Nasir., \& Khan, Muslim (2011). Arch Forms Among Different Angle Classifications A-Study. Pakistasn Oral \& Dental Journal, 21(1) 